\title{
Differential serotonin transport is linked to the rh5-HTTLPR in peripheral blood cells
}

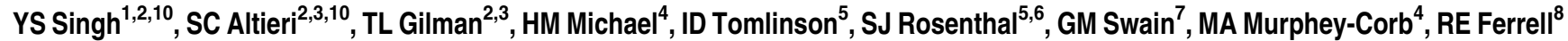 \\ and AM Andrews $\mathbf{s}^{2,3,9}$
}

The human serotonin transporter (SERT) gene possesses a 43-base pair (bp) insertion-deletion promoter polymorphism, the h5-HTTLPR. Genotype at this locus correlates with variation in anxiety-related personality traits and risk for major depressive disorder in many studies. Yet, the complex effects of the h5-HTTLPR, in combination with closely associated single-nucleotide polymorphisms (SNPs), continue to be debated. Moreover, although SERT is of high clinical significance, transporter function in vivo remains difficult to assess. Rhesus express a promoter polymorphism related to the h5-HTTLPR. The rh5-HTTLPR has been linked to differences in stress-related behavior and cognitive flexibility, although allelic variations in serotonin uptake have not been investigated. We studied the serotonin system as it relates to the 5-HTTLPR in rhesus peripheral blood cells. Sequencing of the rh5-HTTLPR revealed a 23-bp insertion, which is somewhat longer than originally reported. Consistent with previous reports, no SNPs in the rh5-HTTLPR and surrounding genomic regions were detected in the individuals studied. Reductions in serotonin uptake rates, cell surface SERT binding, and 5-hydroxyindoleacetic acid/serotonin ratios, but not SERT mRNA levels, were associated with the rh5-HTTLPR short allele. Thus, serotonin uptake rates are differentiable with respect to the 5-HTTLPR in an easily accessible native peripheral tissue. In light of these findings, we foresee that primary blood cells, in combination with high sensitivity functional measurements enabled by chronoamperometry, will be important for investigating alterations in serotonin uptake associated with genetic variability and antidepressant responsiveness in humans.

Translational Psychiatry (2012) 2, e77; doi:10.1038/tp.2012.2; published online 7 February 2012

\section{Introduction}

A number of polymorphisms in human genes coding for key proteins that regulate serotonin $(5-\mathrm{HT})$ neurotransmission have been discovered. Among these are functional polymorphisms in the transcriptional control and noncoding regions of the serotonin transporter gene (SERT; SLC6A4). ${ }^{1-4}$ A 43-base pair (bp) insertion/deletion polymorphism in the promoter region of the human SERT gene, termed the 5-HT transporter-linked polymorphic region (h5-HTTLPR; Figure 1), has received considerable attention owing to its purported relationship with anxietyrelated personality traits, ${ }^{5-7}$ stress-associated depression, ${ }^{8,9}$ amygdala activation in response to negative stimuli, ${ }^{10,11}$ and suicide. $^{12}$

The h5-HTTLPR is thought to influence behavioral characteristics by driving allele-specific SERT promoter activity giving rise to two-fold variability in mRNA levels. ${ }^{1,13}$ Decreases in SERT protein binding in postmortem human brain and $\left[{ }^{3} \mathrm{H}\right] 5-\mathrm{HT}$ uptake in human platelets and immortalized lymphoblasts have been reported to be associated with the h5-HTTLPR short ' $S$ ' allele. ${ }^{1,14,15}$ However, studies on human SERT-binding potential by positron emission tomography (PET) ${ }^{16-18}$ and mRNA levels in postmortem raphe tissue $^{19}$ are not in agreement with earlier findings. Additional common noncoding polymorphisms thought to influence SERT transcription including an intron 2 VNTR, and rs25531 and rs25532 single-nucleotide polymorphisms (SNPs) in the h5-HTTLPR region, have been discovered, adding to the complexity of assessing variability associated with the human SERT gene. ${ }^{2,4,20}$ Nonetheless, although the timing ${ }^{21}$ and specific molecular effects of the h5-HTTLPR on SERT expression and transporter function in the human brain are unresolved, parallels continue to be drawn between this polymorphism and anxiety-related traits and susceptibility to depression. ${ }^{22-27}$

Similar to humans, macaques express a SERTlinked polymorphic region (rh5-HTTLPR; Figure 1). ${ }^{28-30}$ The

\footnotetext{
${ }^{1}$ Department of Chemistry, Pennsylvania State University, University Park, PA, USA; ${ }^{2}$ Department of Psychiatry, Semel Institute for Neuroscience \& Human Behavior, and Hatos Center for Neuropharmacology, David Geffen School of Medicine, and California NanoSystems Institute, University of California, Los Angeles, CA, USA; ${ }^{3}$ Huck Institutes of the Life Sciences, Pennsylvania State University, University Park, PA, USA; ${ }^{4}$ Department of Microbiology and Molecular Genetics, University of Pittsburgh School of Medicine, Pittsburgh, PA, USA; ${ }^{5}$ Department of Chemistry, Vanderbilt University, Nashville, TN, USA; ${ }^{6}$ Departments of Physics, Chemical \& Biomolecular Engineering, and Pharmacology, Vanderbilt University, Nashville, TN, USA; ${ }^{7}$ Department of Chemistry, Michigan State University, East Lansing, MI, USA; ${ }^{8}$ Department of Human Genetics, University of Pittsburgh School of Medicine, Pittsburgh, PA, USA and ${ }^{9}$ Department of Veterinary and Biomedical Sciences, Pennsylvania State University, University Park, PA, USA

Correspondence: Dr AM Andrews, Department of Psychiatry, Semel Institute for Neuroscience \& Human Behavior, and Hatos Center for Neuropharmacology, David Geffen School of Medicine, and California NanoSystems Institute, University of California, Neuroscience Research Building, Room 507,635 Charles E. Young Dr S, Box 957332, Los Angeles, CA 90095-7332, USA.

E-mail: aandrews@mednet.ucla.edu

${ }^{10}$ These authors contributed equally to this work.

Keywords: anxiety; biomarker; chronoamperometry; depression; lymphocytes; SERT
}

Received 20 Septemeber 2011; revised 10 November 2011; accepted 6 December 2011 
a

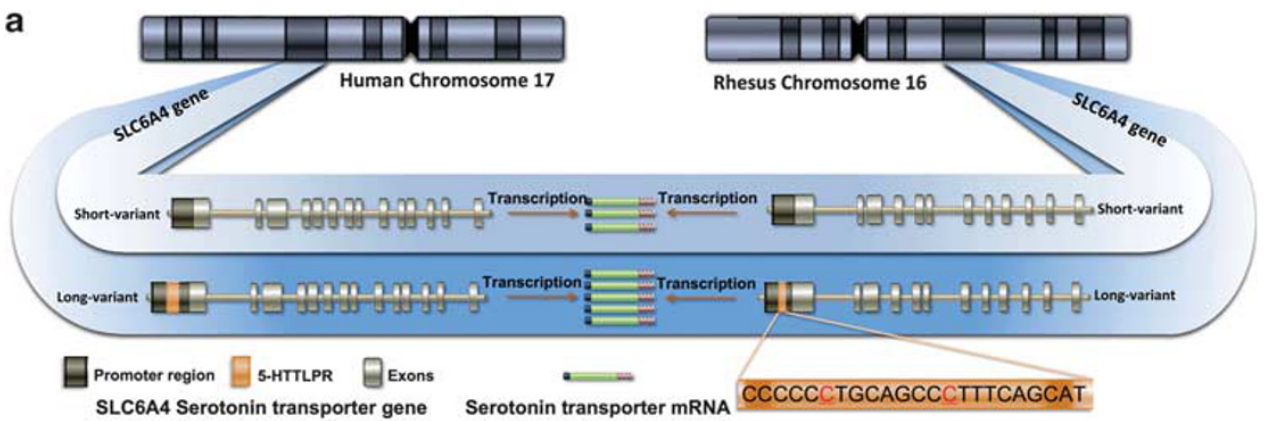

b

OldSeq ccctgctgcagccctcccagcatctccctg $\operatorname{cocccctcctaggatctcccctgcaccccccattatcctccctacaccccccagcatcccccctgcagcc}$ NewSeq ccctgctgcagccctcccagcatctccctgtacccctcctaggatctcccctgcaccccccattatcctccctacaccccccagcatcccccctgcagcc Sometimes g noise as well

OldSeq tcccagcatctcccctgcacccccagcatCCCCC:TGCAGCC:TTTCAGCATccccctgcacccctcccaggatctcccttgcatccccattatctcc NewSeq tcccagcatctcccctgcaccccccagcatCCCCCCTGCAGCCCTTTCAGCAT: $c c c c c t g c a c c c c t c c c a g g a t c t c c c t t g c a t c c c c a t t a t c t c c$ Long Form Seq

OldSeq cctgcacccctcgcagtatccccccgcacctccattatcccccctgcacccttgcggcatcccccctacaccccccagtattccccctgcagcaccccc NewSeq cctgcacccctcgcagtatccccccgcacctccattatcccccctgcacccttgcggcatccccctacacccccagtattcccctgcagcaccccc

OldSeq cagcatctccccegcaccgcccagcatcccccctgcagcccttcccagcaaccccctgcatccctcccaggatctcccctg NewSeq cagcatctcccccgcaccgcccagcatcccccctgcagcccttcccagcaaccccctgcatccctcccaggatctcccctg Internal primer $\boldsymbol{R}$

Figure 1 Structure and sequence of the rhesus 5-HTTLPR. (a) The serotonin transporter (SERT) gene in rhesus monkeys has been reported to contain a 21-bp insertiondeletion polymorphism in the promoter region termed the rh5-HTTLPR. A 43-bp polymorphism, the h5-HTTLPR, occurs in the human SERT gene. In humans, the presence of the 5-HTTLPR short ' $S$ ' allele has been associated with decreased gene transcription and thus, reductions in SERT protein levels and uptake function. We investigated whether the rh5-HTTLPR ' $S$ ' allele is associated with decreased serotonin system parameters in PBCs, which natively express SERT. (b) Sequencing of the rh5-HTTLPR in the 15 animals studied revealed an insertion/deletion region consisting of $23 \mathrm{bp}$, as well as two additional sequence discrepancies (shown in red) compared with the originally published sequence. ${ }^{28}$

rh5-HTTLPR was originally reported to consist of a 21 -bp insertion/deletion involving repeat element 7 at a slightly shifted locus from that in humans. ${ }^{28}$ In contrast to humans, no SNPs associated with the rh5-HTTLPR have been discovered. ${ }^{30}$ Yet similar to humans, stress responsiveness, social behavior, and cognitive performance are influenced by rh5-HTTLPR genotype. For example, behavioral and hormonal responses to early life stress and sensitivity to alcohol are potentiated in macaques bearing a short ' $S$ ' allele. ${ }^{29,31-33}$ Moreover, rhesus with an ' $S$ ' allele showed greater anxiety and fearful behavior ${ }^{34}$ and enhanced aversion to social threats. ${ }^{35}$ Also similar to humans, rhesus short allele carriers perform better on a number of cognitive tasks supporting the idea that the short 5-HTTLPR allele might be associated with evolutionary advantage. ${ }^{36-38}$ SERT immunoreactive fibers have been mapped to the central nucleus of the amygdala ${ }^{39}$ and oxytocin-expressing neurons in the paraventricular nucleus $^{40}$ in rhesus suggesting that differences in SERT expression and uptake function modulate fear responses and social affiliation, respectively.

The rh5-HTTLPR is hypothesized to influence SERT gene transcription; the short allele has been associated with decreased reporter gene expression. ${ }^{29}$ However, studies on SERT mRNA levels in blood cells ${ }^{41}$ or SERT-binding potential using $P E T^{37,42}$ have failed to find associations with respect to rh5-HTTLPR genotype. Otherwise, direct investigations into the effects of the rh5-HTTLPR on SERT function have been lacking. We recently reported on differences in uptake at a single concentration of serotonin in peripheral blood cells
(PBCs) in association with the rh5-HTTLPR. ${ }^{43}$ Uptake rates for serotonin were reduced in macaques carrying one or two ' $S$ ' alleles compared with individuals homozygous for the long allele. In the present study, we investigated native blood cells as biomarkers for a wide range of serotonin system characteristics. We assessed the expression and function of SERTs in rhesus PBCs by analyzing mRNA levels, surface SERT binding $\left(K_{\mathrm{D}}\right.$ and $\left.B_{\max }\right)$, transporter kinetics $\left(K_{\mathrm{M}}\right.$ and $\left.V_{\max }\right)$, and cellular concentrations of serotonin and 5-hydroxyindoleacetic acid (5-HIAA) with respect to rh5-HTTLPR genotype. Investigating rhesus PBCs confers a number of key advantages. (1) Rhesus monkeys are closely related to humans in that they show a genetically similar but less complex form of the 5-HTTLPR. (2) Macaques are animal models whereby in vivo measurements in the brain are possible to assess alterations in SERT function and extracellular serotonin levels directly. ${ }^{44,45}$ (3) Parallels can be drawn between SERT function in the brain vs PBCs in rhesus with relevance to diagnosing and treating psychiatric disorders in humans.

\section{Materials and methods}

Animals. Venous blood was collected under anesthesia from a group of mixed sex rhesus ( $M$. mulatta) $6.9 \pm 0.1$ years of age. Whole blood was used for DNA isolation by established protocols. Animals were genotyped for the rh5-HTTLPR using previously described methods. ${ }^{28}$ 
Genotypes were also determined for tryptophan hydroxylase-2 SNPs and a monoamine oxidase-A repeat length polymorphism $^{30}$ and are reported in the Supplementary Information (Supplementary Table S1). We had the opportunity to genotype a relatively large cohort of animals and thereby, were able to identify and to include a substantial number of individuals with the $S / S$ genotype. However, animals were donated for the present study and constraints on the size of this donation dictated that only a subset of the genotyped cohort could be studied here. Thus, animals were selected to maximize rh5-HTTLPR genotype distributions, particularly $S / S$ and $L / L$ genotypes, and to control for sex and genotypes at the other loci where possible. Information on the final cohort appears in the Supplementary Information (Supplementary Table S1). The genotype distribution for the study cohort was $N=6$ for $L / L, N=3$ for $S / L$, and $N=6$ for $S / S$. Animals from China vs the United States (LABS of Virginia, Yemassee, SC, USA) are noted in Supplementary Table S1 and are distributed across genotypes. Animals were housed at the University of Pittsburgh in pairs, with the exception of large males who were housed singly. Individual blood samples $(\sim 40 \mathrm{ml})$ were collected and PBCs were isolated from genotyped subjects. Experiments for protocol development were conducted using pooled mixed genotype rhesus PBCs. All work involving animals was carried out in accordance with National Institutes of Health guidelines and was approved by the University of Pittsburgh School of Medicine Institutional Animal Care and Use Committee.

Cell survival and SERT function. Confocal microscopy and flow cytometry were carried out using IDT307 (4-(4(dimethylamino) phenyl)-1-methylpyridinium iodide), a monoamine transporter substrate similar to $\mathrm{ASP}^{+}$ (4-(4-diethylaminostyryl)- $N$-methylpyridinium iodide). ${ }^{46,47}$ Following uptake, IDT307 fluoresces enabling transporter function in PBCs to be determined optically.

Serotonin uptake. PBCs ( $\sim 10$ million cell per $\mathrm{ml}$ ) were thawed by adding assay buffer $(12-15 \mathrm{ml})$ at room temperature. A small volume $(200 \mu \mathrm{l})$ of cells in solution was used for live cell counts using Trypan blue exclusion. Cells were centrifuged at $340 \mathrm{~g}$ for $7 \mathrm{~min}$. Pellets containing PBCs were resuspended by gently vortexing in assay buffer to produce final concentrations of 2-4 million cells per $\mathrm{ml}$. Chronoamperometry was carried out, as described previously, ${ }^{43}$ using boron-doped diamond microelectrodes ${ }^{48}$ to measure serotonin-uptake rates on a second-by-second basis over a range of serotonin concentrations to determine maximal uptake rates $\left(V_{\max }\right)$ and affinity constants $\left(K_{\mathrm{M}}\right)$. We have shown that the use of chronoamperometry enables biologically important differences in uptake rates to be distinguished, which cannot otherwise be differentiated by radiochemical methods. ${ }^{49}$

Cell surface SERT binding. SERT binding was performed using the cocaine analog $\left({ }^{125} \mathrm{I}\right) \mathrm{RTI}-55$ by previously published methods with minor modifications. ${ }^{50,51}$ As samples from genotyped animals were limited, we focused on determining surface SERT binding (as opposed to total
SERT) due to its greater relevance to serotonin uptake and antidepressant action. Cells ( $\sim 10$ million cells per $\mathrm{ml}$ ) were thawed and centrifuged as described above. Pellets containing intact cells were divided to measure specific and nonspecific binding over a range of RTI-55 concentrations to determine maximal binding $\left(B_{\max }\right)$ and dissociation constants $\left(K_{\mathrm{D}}\right)$.

SERT mRNA levels. Total RNA was isolated from PBCs ( 8-9 million cells per sample) using isoamyl/chloroform phase separation and isopropanol precipitation. Real-time quantitative PCR (RT-qPCR) and TaqMan probes and primers specific to SERT and two control genes, ACTB ( $\beta$-actin) and GAPDH (glyceraldehyde 3-phosphate dehydrogenase), were used for amplifications. Sequences and efficiencies of the primer/probe sets are reported in Supplementary Table S2.

Neurotransmitter levels. Blood cell concentrations of 5-HT and its major metabolite, 5-HIAA, were determined using previously published procedures ${ }^{52}$ by high-performance liquid chromatography with electrochemical detection.

Statistics. All values are expressed as means \pm standard errors (s.e.m.s) with differences of $P<0.05$ considered statistically significant. Significant differences are denoted in the figures as ${ }^{\star} P<0.05,{ }^{\star \star} P<0.01$, and ${ }^{\star \star \star} P<0.001$.

Additional information on electrochemical uptake, ( $\left.{ }^{125} \mathrm{I}\right) \mathrm{RTI}-55$ binding, mRNA isolation, RT-qPCR, neurochemical analysis, chemicals, and statistics appears in the Supplementary Information.

\section{Results}

The rh5-HTTLPR comprises a 23-bp polymorphism. The genomic region 130-bps upstream and 227-bps downstream of the rh5-HTTLPR was sequenced for each of the 15 animals studied. Sequences were identical for all individuals (Figure 1b). A number of differences were noted compared with the original sequence published by Lesch et al. ${ }^{28}$ One $\mathrm{C} / \mathrm{T}$ discrepancy was identified upstream of the rh-5HTTLPR polymorphic region. Within the insertion region itself, two additional cytosines were detected suggesting that the rh5-HTTLPR consists of $23 \mathrm{bps}$, instead of $21 \mathrm{bps}$ as originally reported. Additionally, the $3^{\prime}$ region immediately flanking the rh5-HTTLPR contained one less cytosine than previously reported. Most discrepancies were associated with strings of cytosines, where sequencing errors commonly occur. However, we cannot rule out genetic heterogeneity in this region as possibly accounting for discrepancies with previously reported sequences.

Previously frozen PBCs are viable and transport serotonin. The effects of frozen storage on the quality of PBCs were assessed using flow cytometry and confocal imaging. Propidium iodide was used to identify dead cells. We found that $\sim 75 \%$ of cells were alive after thawing and significant changes in cell viability did not occur when cells were 
maintained at $4{ }^{\circ} \mathrm{C}$ for up to $4 \mathrm{~h}$ (Supplementary Figure S1). Studies using flow cytometry in conjunction with IDT307, a fluorescent monoamine transporter substrate, ${ }^{46,47}$ illustrated that $\mathrm{PBCs}$ retain transporter function after isolation, freezing and thawing (Supplementary Figure S2). Confocal imaging showed localization of IDT307 inside the majority of live cells (Figure 2), also indicating intact transporter function.

Using chronoamperometry to make highly time-resolved measurements, we previously demonstrated that serotonin uptake by rhesus PBCs is $\mathrm{Na}^{+}$-dependent. ${ }^{43}$ Additionally, uptake is abolished after preincubation with the serotoninselective reuptake inhibitor paroxetine. Here, we investigated the effects of oxygen on serotonin clearance rates in rhesus PBCs. Similar to synaptosomes, ${ }^{49,53}$ we observed a $40 \%$ increase in serotonin uptake in the presence of oxygenated assay buffer (Supplementary Figure S3). Changes in serotonin uptake rates were not observed after blocking norepinephrine transporters, dopamine transporters or organic cation type 3 transporters ${ }^{54}$ (Supplementary Figure S3). These results, in combination with prior findings, suggest that extracellular serotonin clearance by rhesus PBCs is a SERT-mediated active uptake process.
Reduced serotonin uptake and surface SERT binding are associated with the rh5-HTTLPR short allele. Recently, we reported that PBCs isolated from individuals expressing the rh5-HTTLPR ' $S$ ' allele showed reduced uptake of $0.5 \mu \mathrm{M}$ serotonin. ${ }^{43}$ Here, we used chronoamperometry to investigate uptake over a range of serotonin concentrations to determine maximal uptake rates $\left(V_{\max }\right)$ and affinity constants $\left(K_{\mathrm{M}}\right)$. The 'S' allele of the rh5-HTTLPR was associated with significant decreases in maximal serotonin uptake rates (Figure $3 a$ ) but not the affinity of SERT for serotonin (Supplementary Table S3). Maximal uptake rates were 7.1 $\pm 0.4,5.1 \pm 0.2$, and $4.9 \pm 0.6 \mathrm{pmol}$ per million cells per min and affinity constants were $0.45 \pm 0.06,0.39 \pm 0.05$, and $0.45 \pm 0.1 \mu \mathrm{M}$ for $L / L, S / L$, and $S / S$ genotypes, respectively.

Binding of RTI-55 was used to investigate SERT protein localized at the plasma membrane in undisrupted cells. Surface SERT binding showed a trend toward a decrease in maximal binding in ' $S$ ' allele carriers (Figure $3 \mathrm{~b} ; P<0.12$ ). No differences in dissociation constants were detected (Supplementary Table S3). Maximal surface SERT binding was $3.5 \pm 0.4,2.4 \pm 0.4$, and $2.6 \pm 0.4$ fmol per million cells and dissociation constants were $0.27 \pm 0.04$, $0.29 \pm 0.08$, and $0.26 \pm 0.07 \mathrm{nM}$ in $L / L, S / L$, and $S / S$ genotypes, respectively.

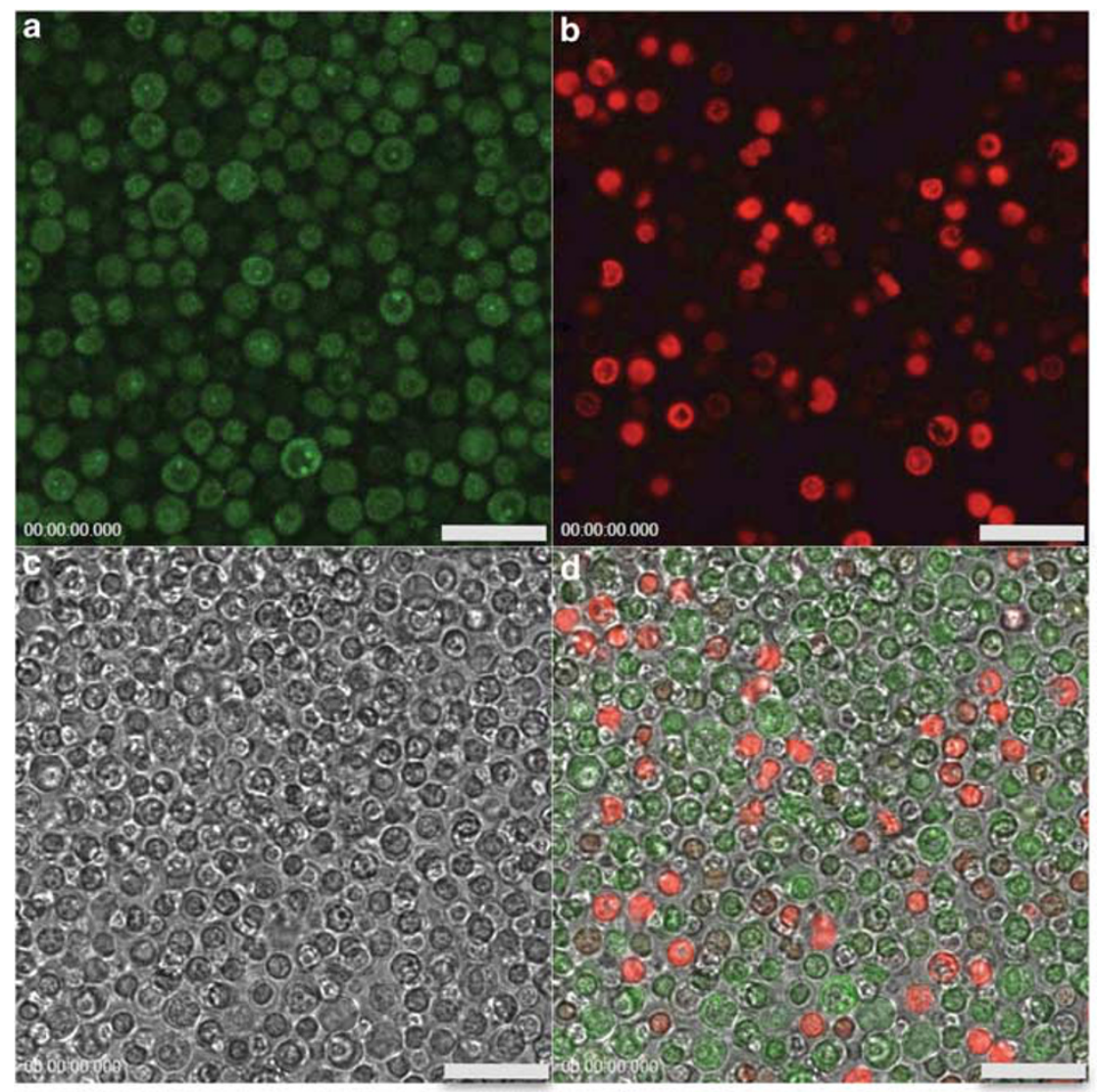

Figure 2 Confocal images of rhesus PBCs. Cells were incubated with (a) $1 \mu \mathrm{M} \mathrm{IDT307} \mathrm{(30} \mathrm{min)} \mathrm{and} \mathrm{(b)} \mathrm{propidium} \mathrm{iodide} \mathrm{(5} \mathrm{min).} \mathrm{Propidium} \mathrm{iodide} \mathrm{(excitation} 536 \mathrm{~nm}$, emission $617 \mathrm{~nm}$ ) stains dead cells, whereas IDT307 (excitation $485 \mathrm{~nm}$, emission $520 \mathrm{~nm}$ ), a substrate for SERTs, fluoresces after being taken up into live cells. (c) A differential interference contrast image shows all cells. (d) There is no overlap between cells predominantly labeled with IDT307 (green) vs propidium iodide-labeled cells (red) in the overlay of all three images demonstrating functional SERTs in living cells. Scale bars are $25 \mu \mathrm{m}$. 

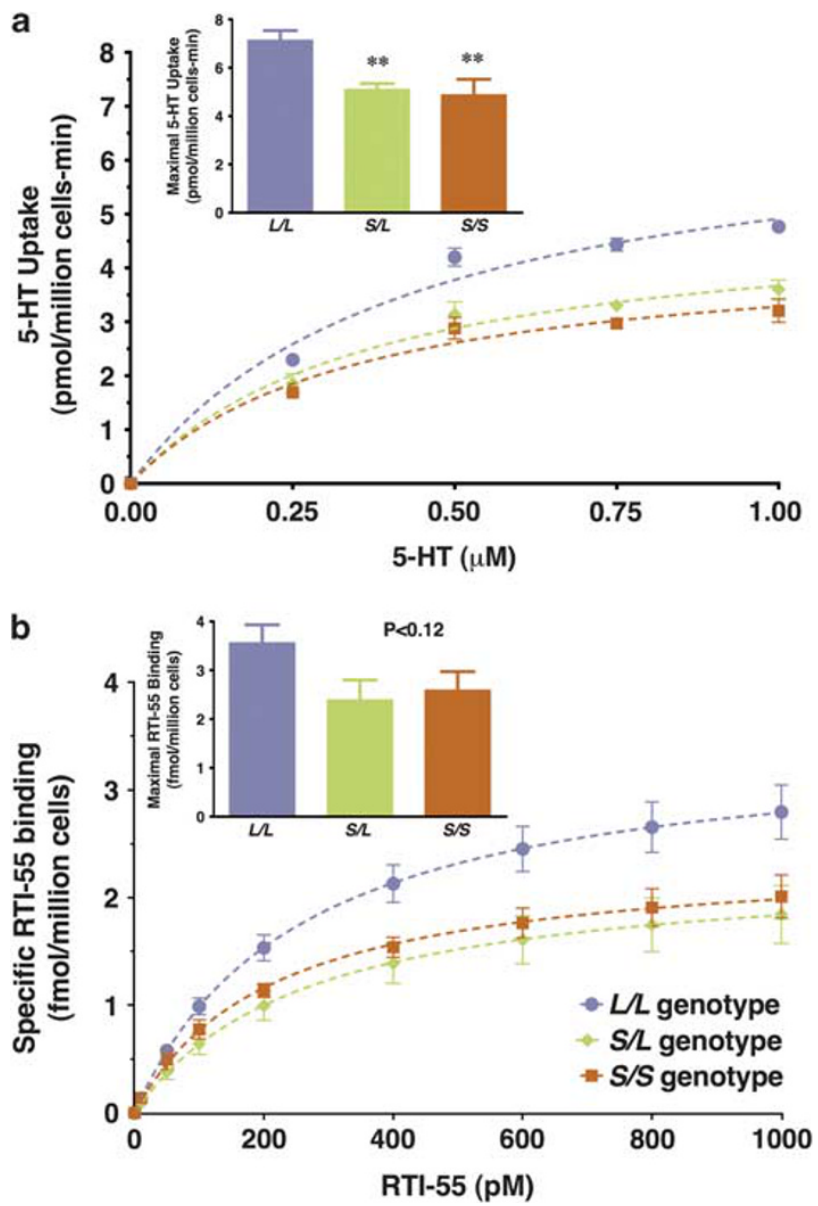

Figure 3 Serotonin uptake rates and surface SERT binding in rhesus PBCs. (a) Maximal uptake rates were calculated using nonlinear curve fitting for data from individual animals. Mean maximal uptake rates with respect to genotype are shown in the inset. One-way analysis of variance indicated that maximal uptake rates vary with respect to rh5-HTTLPR genotype $(F(2,12)=5.9 ; \quad P<0.05)$. A priori comparisons of uptake rates using one-tailed Student's $t$-tests showed significan decreases associated with the ' $S$ ' allele $(t=3.4, d f=7, P<0.01 \mathrm{~L} / L$ vs $S / L$ and $t=3.0, d f=10, P<0.01 \mathrm{~L} / \mathrm{L}$ vs $S / S)$. (b) Binding of $\left({ }^{125} \mid\right) \mathrm{RTI}-55$ to intact PBCs was used to determine the levels of SERT located at the plasma membrane. Maximal binding was calculated for data from individual animals by nonlinear curve fitting using one-site saturation isotherms. Mean maximal binding as a function of genotype is shown in the inset. There was a trend toward decreased SERT binding associated with the ' $S$ ' allele $(F(2,12)=2.5 ; P<0.12)$. Data are means \pm s.e.m.s with $N=6$ for $L / L, N=3$ for $S / L$, and $N=6$ for $S / S$. ${ }^{*} P<0.01$ vs the $L / L$ genotype.

In addition to analyzing these data with respect to individual genotypes, we combined data for the $S / L$ and $S / S$ groups. Merging data from short allele carriers has been carried out previously due to a purported 'dominant' effect of the short allele and/or with smaller group sizes. ${ }^{1,37,55}$ Significant differences between animals homozygous for the rh5-HTTLPR ' $L$ ' allele and animals expressing one or two copies of the ' $S$ ' allele were present for serotonin uptake rates and cell surface SERT binding (Figures $4 a$ and $b$ ). No significant differences in affinity constants for uptake $\left(K_{\mathrm{M}}\right)$ or binding $\left(K_{\mathrm{D}}\right)$ were found when the $S / L$ and $S / S$ genotypes were merged. Together, both modes of analysis suggest that reductions in serotonin uptake rates in rhesus PBCs from ' $S$ ' allele carriers are associated with decreases in surface SERT availability but not the affinity of SERT for serotonin or RTI-55.
SERT mRNA levels do not differ with respect to rh5-HTTLPR genotype. The h5-HTTLPR is hypothesized to influence SERT mRNA levels whereby the presence of the ' $S$ ' allele is associated with reduced transcriptional efficiency. ${ }^{1,56}$ We investigated whether the rh5-HTTLPR confers effects associated with differential transcription. In contrast to surface SERT binding and function, we did not find differences in SERT mRNA levels in rhesus PBCs with respect to rh5-HTTLPR genotype (Supplementary Figure $S 4 A)$ or when the $S / L$ and $S / S$ genotypes were merged (Figure 4c).

Ratios of 5-HIAA/5-HT are decreased in association with the rhesus ' $S$ ' allele. We measured serotonin and 5-HIAA concentrations in PBCs to investigate alterations associated with the rh5-HTTLPR. We found that 5-HT levels were not different with respect to genotype (Supplementary Figure S4B). However, we observed a significant decrease in 5-HIAA levels in association with genotypes having one or two copies of the ' $S$ ' allele (Supplementary Figure S4C). Significant decreases in 5-HIAA to 5-HT ratios were observed for $S / S$ vs $L / L$ groups (Supplementary Figure $S 4 D)$ and when the $S / L$ and $S / S$ genotypes were combined (Figure 4f).

\section{Discussion}

The human 5-HTTLPR is postulated to drive allele-specific SERT promoter activity leading to differences in mRNA and protein levels, and functional serotonin uptake (Figure 1). ${ }^{1}$ Here, we investigated each of these aspects of SERT expression and function, in addition to serotonin and 5-HIAA concentrations, to elucidate the effects of the rh5-HTTLPR in native (untransformed) PBCs. We find that the short allele of the rh5-HTTLPR is associated with reduced surface SERT binding, which is correlated on an individual basis with serotonin uptake rates (Figure 5a). By contrast, differences in mRNA levels with respect to genotype were not detected; nor was there a correlation between individual SERT mRNA levels and surface SERT protein binding (Figure $5 b$ ).

Lesch and co-workers reported lower promoter activity associated with the h5-HTTLPR short variant. ${ }^{56}$ Decreases in SERT mRNA, SERT binding, and serotonin uptake have also been associated with the 5-HTTLPR short allele in human lymphoblastoid (transformed) cell lines. ${ }^{1}$ Subsequent studies of serotonin uptake in human platelets support these findings ${ }^{15,57,58}$ with one exception. ${ }^{59}$ By contrast, binding studies in platelets measuring total SERT protein report variable results with respect to the h5-HTTLPR. ${ }^{15,58-60}$ Postmortem brain tissue and in vivo brain-imaging studies are similarly associated with conflicting results. ${ }^{14,16,18,61-64}$ Contradictory findings in human studies are attributable to a number of factors such as small samples sizes, subject genetic variability, the influence of environmental/developmental factors, and the use of insufficiently sensitive analytical methods. ${ }^{38,43,49,65}$

Notably, the interpretation of the results of investigations into the human SERT gene are complicated by additional common noncoding SERT gene polymorphisms thought to influence transcription. These and other factors make direct 
a

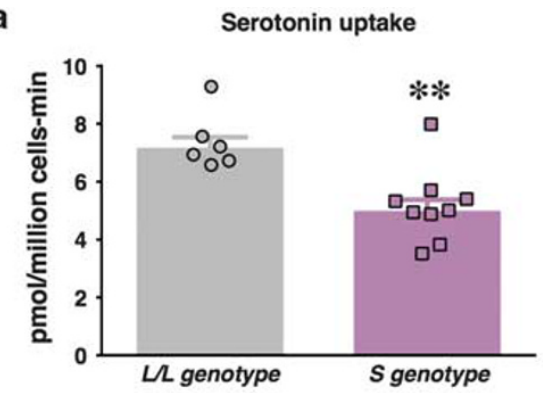

C

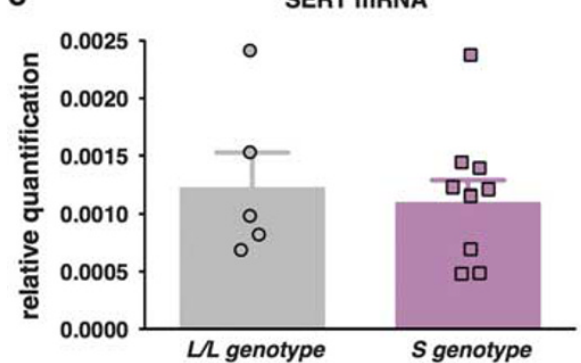

e

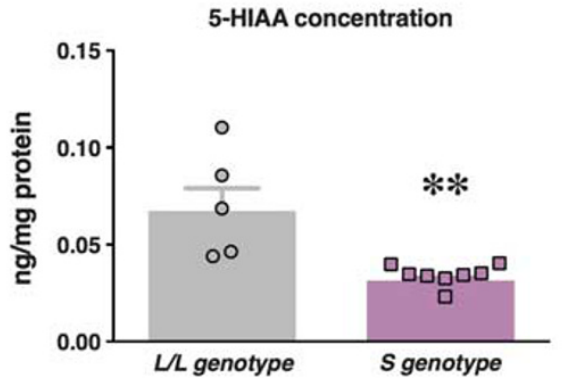

b

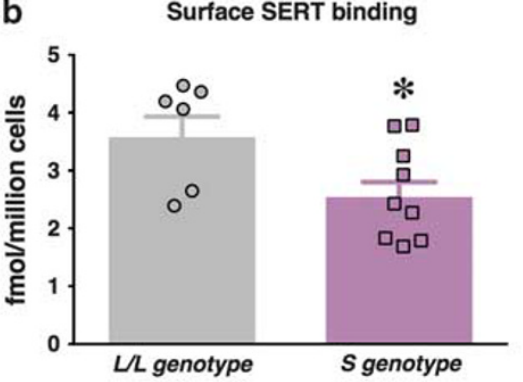

d
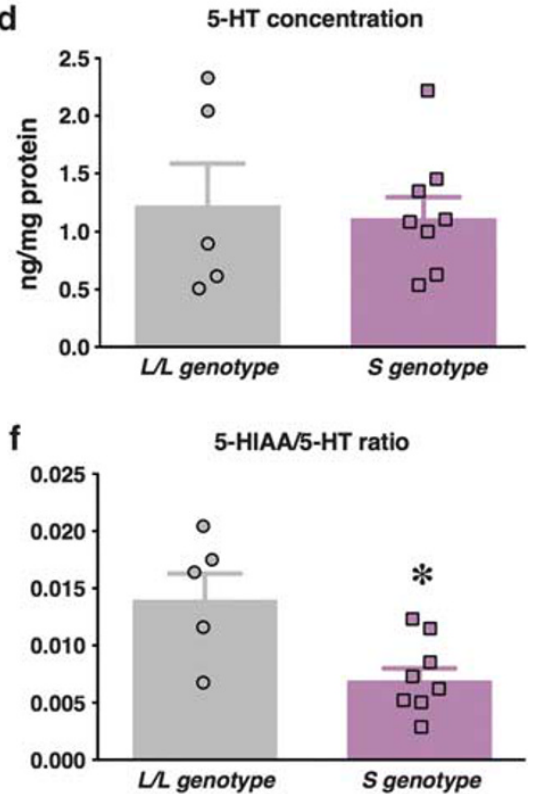

Figure 4 Serotonin system characteristics associated with the rh5-HTTLPR short allele in PBCs. Experimental data from $S / L$ and $S / S$ genotypes were merged and means \pm s.e.m.s are shown for (a) maximal serotonin uptake, (b) maximal surface SERT binding, (c) SERT mRNA levels, (d) 5-HT concentrations, (e) 5-HIAA concentrations and (f) 5-HIAA to 5-HT ratios. Data for animals having one or two ' $S$ ' alleles $(S / L$ and $S / S$ ) were compared with data from animals with the $L / L$ genotype using one-tailed $t$ tests ( $t=3.6, d f=13, P<0.01$ for maximal serotonin uptake, $t=2.3, d f=13, P<0.05$ for maximal SERT binding) or two-tailed $t$ tests $(t=3.7, d f=11, P<0.01$ for 5 -HIAA concentrations, and $t=3.0, d f=11, P<0.05$ for $5-\mathrm{HIAA} / 5-\mathrm{HT}$ ratios). Individual values for each animal are shown as scatter plots overlaid on the respective bar graphs. Data are means \pm s.e.m.s with $N=5-6$ for $L / L$ and $N=8-9$ for ' $S$ ' genotypes. ${ }^{* *} P<0.01$ and ${ }^{*} P<0.05$ vs the $L / L$ genotype.

correlations between the h5-HTTLPR and changes in serotonin system expression and function challenging (see Singh et al. $^{43}$ for further discussion). Recent controversies have arisen regarding the role of the h5-HTTLPR, particularly with regard to stress-associated depression. ${ }^{24,25,66-69}$ The results of the current study present a comprehensive assessment of the cellular phenotype of the short vs long alleles providing solid evidence for a functional effect of the rh5-HTTLPR. One of the major advantages of the nonhuman primate model studied here is that unlike in human studies, subjects' environments can be highly regulated and manipulated over various periods in the lifespan. ${ }^{29,32,33,70,71}$ Furthermore, data can be collected from subjects whose genetic relatedness is knowable and controllable. Neither early life environment nor the pedigrees of the animals in the present study were highly homogeneous; animals from China and the United States were represented across genotypes. Nonetheless, rh5-HTTLPR short allele carriers were characterized by reduced serotonin uptake rates, cell surface SERT binding, and intracellular 5-HIAA levels in PBCs.
In the present study, SERT mRNA levels measured by RTqPCR in rhesus PBCs were not significantly different with respect to rh5-HTTLPR genotype. This finding is consistent with a previous report on SERT mRNA in PBCs from a large cohort of rhesus ( 80 animals). ${ }^{41}$ Postmortem human brain studies highlight the variability in SERT mRNA levels such that within the same genotype, 10-fold differences in SERT mRNA are observed. ${ }^{14}$ Similarly, in human lymphoblasts, SERT mRNA levels vary by $5-10$-fold even when controlling for trialleic genotype with only $8 \%$ of the variance arising from measurement contributions. ${ }^{3}$ Variability in SERT mRNA could be due to a number of factors unrelated to 5-HTTLPR genotype that influence mRNA synthesis, stability and degradation. Most studies in native tissues or cells from humans or rhesus fail to find associations between SERT mRNA and 5-HTTLPR genotype, suggesting that mRNA levels are a poor indicator of variability associated with the 5-HTTLPR.

The h5-HTTLPR has not yet been precisely modeled in rodents, although there are similarities with SERT-deficient mice and rats, whereby the low-functioning $h 5-H T T L P R$ allele is hypothesized to confer similar reductions in SERT expres- 

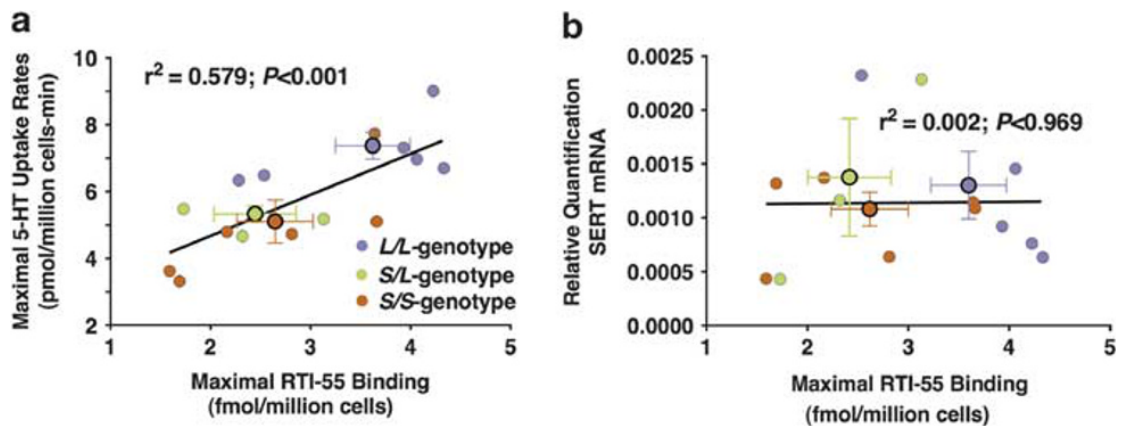

Figure 5 Correlations between surface SERT binding vs serotonin uptake or SERT mRNA levels. Correlations are shown with respect to individual animals between (a) SERT function and surface SERT binding and (b) SERT mRNA levels and surface SERT binding. Mean values with respect to genotype are shown as larger symbols with s.e.m.s for each variable indicated. Only SERT function and surface SERT binding are correlated, such that $60 \%$ of the variance is shared with a low probability of chance correlation $(P<0.001)$.

sion and function to those occurring with constitutive loss of one functional SERT allele in rodents. ${ }^{53,65,72-74}$ Mice with constitutive reductions in SERT gene expression show elevated anxiety-related behavior, ${ }^{75}$ enhanced stress reactivity, ${ }^{76-78}$ and in some background strains, increased depressive-like behavior. ${ }^{79}$ Increased anxiety-like behavior ${ }^{80}$ and amygdala over-activity ${ }^{81}$ are associated with constitutive reductions of SERT in rats.

In mice, life-long absence of SERT is associated with decreased brain tissue serotonin concentrations. ${ }^{50,82,83} \mathrm{How}$ ever, mice with a $50 \%$ constitutive loss of SERT expression show little to no change in brain tissue serotonin. Here, rhesus PBCs showed no significant differences in serotonin levels. Yet, 5-HIAA was reduced in PBCs from rhesus ' $S$ ' allele carriers. In light of decreased serotonin uptake in rhesus PBCs associated with the ' $S$ ' allele, these data suggest that a feedback mechanism might be at work to conserve available serotonin. Antidepressant administration in rhesus has been associated with decreased 5-HIAA concentrations in cerebrospinal fluid. ${ }^{84}$ Investigation of serotonin synthesis and degradation rates with respect to the rh5-HTTLPR will be required to elucidate the underlying nature of the differences in 5-HIAA levels in rhesus PBCs.

Altered stress and anxiety responses exhibited by SERTdeficient mice resemble phenotypic characteristics of humans and macaques associated with the short form of the 5-HTTLPR. Studies in rodents show that disruption of SERT function during a key postnatal period results in changes in emotional behaviors in adulthood that share some similarities with constitutive reductions in SERT expression. ${ }^{85,86}$ Developmentally sensitive changes in anxiety-related behavior in rodents, in combination with negative findings in association studies on the $5-H T T L P R$ in adult humans, have led to the idea that the effects of the h5-HTTLPR on serotonin transmission predominate during key developmental periods. ${ }^{21}$ Here, we show that changes in the serotonin system associated with the rh5-HTTLPR are present during adulthood, alternately suggesting that this gene variant influences SERT function and serotonin neurochemistry throughout life, at least in the periphery. Moreover, gene $\times$ environment interactions between rh5-HTTLPR genotype and peer vs mother rearing, with respect to CSF 5-HIAA levels further implicate central effects of the 5-HTTLPR beyond early development. ${ }^{29}$
The present findings suggest that PBCs might be used to study genetic and pharmacologic alterations in serotonin transmission directly and more accessibly than measurements in the central nervous system. PBCs are obtained using minimally invasive methods and can be viably frozen for later study. Additionally, PBCs are native cells; they do not suffer from potential problems associated with altered gene expression associated with immortalization, for example, in lymphoblasts. ${ }^{87}$ Investigating SERT in the brain in vivo in humans is currently only possible via PET imaging. However, a lack of association between SERT binding by PET and 5-HTTLPR genotype is reported in humans ${ }^{16-18,63}$ (discussed in greater detail in Singh et al. ${ }^{43}$ ), as well as in rhesus. ${ }^{37,42}$ Before using PBCs as biomarkers of alterations in the brain serotonin system, additional research clarifying the relationship between the brain and peripheral blood serotonin systems is needed. For instance, there might be important differences between PBCs and the central nervous system in terms of regulatory mechanisms affecting SERT function. Also, PBCs constitute a mixed population of cells consisting of a number of different cell types expressing SERT, that is, mononuclear cells including monocytes and lymphocytes, and small numbers of platelets. Determining the contributions of each of these kinds of cells to uptake rates measured in PBC preparations is the subject of ongoing studies. In any case, the findings of the present study were the same regardless of whether the data were expressed and analyzed with respect to numbers of lymphocytes or total protein levels, the latter of which reflect all relevant cell types (Supplementary Table S3).

Native peripheral cells hold promise as candidates to elucidate central nervous system function at the molecular and genetic levels and with respect to drug mechanisms and efficacy. Furthermore, developing clinically applicable methods to perform functional measurements in PBCs that are sensitive to genetic influence represents a step toward an approach whereby cells readily accessible from human blood samples might be used to predict drug responses, thus initiating the concept of individually tailored therapeutic interventions.

\section{Conflict of interest}

SJ Rosenthal and ID Tomlinson declare financial interests in commercial products involving IDT307. All other authors declare no conflict of interest. 
Acknowledgements. We acknowledge the Cytometry Facility at the Huck Institutes of the Life Sciences, Pennsylvania State University and the Global Bio Lab and GenoSeq Core Facility at the University of California, Los Angeles. We also acknowledge Drs Beatriz Campo-Fernandez and Etienne Sibille for assistance with RT-qPCR experiments and data analysis, respectively, Mr Brendan Beikmann for assistance with confocal microscopy, Drs Erica Unger and Laura Bianco for assistance with the binding assay, and Drs Andrew Leuchter, David Jentsch, and Paul Weiss for critical feedback on the manuscript. This project was supported by funding from the National Institutes of Health (MH064756 to AMA and EB003778 to SJR). The content is solely the responsibility of the authors and does not necessarily represent the official views of the National Institutes of Health.

1. Lesch KP, Bengel D, Heils A, Sabol SZ, Greenberg BD, Petri S et al. Association of anxiety-related traits with a polymorphism in the serotonin transporter gene regulatory region. Science 1996; 274: 1527-1531.

2. Wendland JR, Martin BJ, Kruse MR, Lesch KP, Murphy DL. Simultaneous genotyping of four functional loci of human SLC6A4, with a reappraisal of 5-HTTLPR and rs25531. Mol Psychiatry 2006; 11: 224-226.

3. Hu XZ, Lipsky RH, Zhu G, Akhtar LA, Taubman J, Greenberg BD et al. Serotonin transporter promoter gain-of-function genotypes are linked to obsessive-compulsive disorder. Am J Hum Genet 2006; 78: 815-826.

4. Wendland JR, Moya PR, Kruse MR, Ren-Patterson RF, Jensen CL, Timpano KR et al. A novel, putative gain-of-function haplotype at SLC6A4 associates with obsessivecompulsive disorder. Hum Mol Genet 2008; 17: 717-723.

5. Sen S, Burmeister M, Ghosh D. Meta-analysis of the association between a serotonin transporter promoter polymorphism (5-HTTLPR) and anxiety-related personality traits. $A m$ $J$ Med Genet B Neuropsychiatr Genet 2004; 127B: 85-89.

6. Schinka JA, Busch RM, Robichaux-Keene N. A meta-analysis of the association between the serotonin transporter gene polymorphism (5-HTTLPR) and trait anxiety. Mol Psychiatry 2004; 9: 197-202.

7. Savitz JB, Ramesar RS. Genetic variants implicated in personality: a review of the more promising candidates. Am J Med Genet B Neuropsychiatr Genet 2004; 131B: 20-32.

8. Caspi A, Sugden K, Moffitt TE, Taylor A, Craig IW, Harrington $\mathrm{H}$ et al. Influence of life stress on depression: moderation by a polymorphism in the 5-HTT gene. Science 2003; 301: 386-389.

9. Kendler KS, Kuhn JW, Vittum J, Prescott CA, Riley B. The interaction of stressful life events and a serotonin transporter polymorphism in the prediction of episodes of major depression: a replication. Arch Gen Psychiatry 2005; 62: 529-535.

10. Canli T, Omura K, Haas BW, Fallgatter A, Constable RT, Lesch KP. Beyond affect: a role for genetic variation of the serotonin transporter in neural activation during a cognitive attention task. Proc Natl Acad Sci USA 2005; 102: 12224-12229.

11. von dem Hagen EA, Passamonti L, Nutland S, Sambrook J, Calder AJ. The serotonin transporter gene polymorphism and the effect of baseline on amygdala response to emotional faces. Neuropsychologia 2011; 49: 674-680.

12. Anguelova M, Benkelfat C, Turecki G. A systematic review of association studies investigating genes coding for serotonin receptors and the serotonin transporter: I. Affective disorders. Mol Psychiatry 2003; 8: 574-591.

13. Murphy DL, Lesch KP. Targeting the murine serotonin transporter: insights into human neurobiology. Nat Rev Neurosci 2008; 9: 85-96.

14. Little KY, McLaughlin DP, Zhang L, Livermore CS, Dalack GW, McFinton PR et al. Cocaine, ethanol, and genotype effects on human midbrain serotonin transporter binding sites and mRNA levels. Am J Psychiatry 1998; 155: 207-213.

15. Greenberg BD, Tolliver TJ, Huang SJ, Li Q, Bengel D, Murphy DL. Genetic variation in the serotonin transporter promoter region affects serotonin uptake in human blood platelets. Am J Med Genet 1999; 88: 83-87.

16. Murthy NV, Selvaraj S, Cowen PJ, Bhagwagar Z, Riedel WJ, Peers P et al. Serotonin transporter polymorphisms (SLC6A4 insertion/deletion and rs25531) do not affect the availability of 5-HTT to [11C] DASB binding in the living human brain. Neurolmage 2010; 52: 50-54.

17. Parsey RV, Hastings RS, Oquendo MA, Hu X, Goldman D, Huang YY et al. Effect of a triallelic functional polymorphism of the serotonin-transporter-linked promoter region on expression of serotonin transporter in the human brain. Am J Psychiatry 2006; 163: 48-51.

18. Shioe K, Ichimiya T, Suhara T, Takano A, Sudo Y, Yasuno F et al. No association between genotype of the promoter region of serotonin transporter gene and serotonin transporter binding in human brain measured by PET. Synapse 2003; 48: 184-188.

19. Lim JE, Papp A, Pinsonneault J, Sadee W, Saffen D. Allelic expression of serotonin transporter (SERT) mRNA in human pons: lack of correlation with the polymorphism SERTLPR. Mol Psychiatry 2006; 11: 649-662.

20. Nakamura $M$, Ueno $S$, Sano $A$, Tanabe $H$. The human serotonin transporter gene linked polymorphism (5-HTTLPR) shows ten novel allelic variants. Mol Psychiatry 2000; 5: 32-38.

21. Sibille E, Lewis DA. SERT-ainly involved in depression, but when? Am J Psychiatry 2006; 163: 8-11.

22. Neumeister $A, H u X Z$, Luckenbaugh DA, Schwarz M, Nugent AC, Bonne $O$ et al. Differential effects of 5-HTTLPR genotypes on the behavioral and neural responses to tryptophan depletion in patients with major depression and controls. Arch Gen Psychiatry 2006; 63: 978-986.
23. Zalsman G, Huang YY, Oquendo MA, Burke AK, Hu XZ, Brent DA et al. Association of a triallelic serotonin transporter gene promoter region (5-HTTLPR) polymorphism with stressful life events and severity of depression. Am J Psychiatry 2006; 163: 1588-1593.

24. Wankerl M, Wust S, Otte C. Current developments and controversies: Does the serotonin transporter gene-linked polymorphic region (5-HTTLPR) modulate the association between stress and depression? Curr Opin Psychiatry 2010; 23: 582-587.

25. Caspi A, Hariri AR, Holmes A, Uher R, Moffitt TE. Genetic sensitivity to the environment: the case of the serotonin transporter gene and its implications for studying complex diseases and traits. Am J Psychiatry 2010; 167: 509-527.

26. Kiyohara C, Yoshimasu K. Association between major depressive disorder and a functional polymorphism of the 5-hydroxytryptamine (serotonin) transporter gene: a meta-analysis. Psychiatr Genet 2010; 20: 49-58.

27. Clarke H, Flint J, Attwood AS, Munafo MR. Association of the 5- HTTLPR genotype and unipolar depression: a meta-analysis. Psychol Med 2010; 40: 1767-1778.

28. Lesch KP, Meyer J, Glatz K, Flugge G, Hinney A, Hebebrand J et al. The 5-HT transporter gene-linked polymorphic region (5-HTTLPR) in evolutionary perspective: alternative biallelic variation in rhesus monkeys. Rapid communication. J Neural Transm 1997; 104: 1259-1266.

29. Bennett AJ, Lesch KP, Heils A, Long JC, Lorenz JG, Shoaf SE et al. Early experience and serotonin transporter gene variation interact to influence primate CNS function. $\mathrm{Mol}$ Psychiatry 2002; 7: 118-122.

30. Wendland JR, Lesch KP, Newman TK, Timme A, Gachot-Neveu H, Thierry B et al. Differential functional variability of serotonin transporter and monoamine oxidase a genes in macaque species displaying contrasting levels of aggression-related behavior. Behav Genet 2006; 36: 163-172.

31. Champoux M, Bennett A, Shannon C, Higley JD, Lesch KP, Suomi SJ. Serotonin transporter gene polymorphism, differential early rearing, and behavior in rhesus monkey neonates. Mol Psychiatry 2002; 7: 1058-1063.

32. Barr CS, Newman TK, Becker ML, Champoux M, Lesch KP, Suomi SJ et al. Serotonin transporter gene variation is associated with alcohol sensitivity in rhesus macaques exposed to early-life stress. Alcohol Clin Exp Res 2003; 27: 812-817.

33. Barr CS, Newman TK, Lindell S, Shannon C, Champoux M, Lesch KP et al. Interaction between serotonin transporter gene variation and rearing condition in alcohol preference and consumption in female primates. Arch Gen Psychiatry 2004; 61: 1146-1152.

34. Bethea CL, Streicher JM, Coleman K, Pau FK, Moessner R, Cameron JL. Anxious behavior and fenfluramine-induced prolactin secretion in young rhesus macaques with different alleles of the serotonin reuptake transporter polymorphism (5HTTLPR). Behav Genet 2004; 34: 295-307.

35. Watson KK, Ghodasra JH, Platt ML. Serotonin transporter genotype modulates social reward and punishment in rhesus macaques. PLOS One 2009; 4: e4156.

36. Belsky J, Jonassaint C, Pluess M, Stanton M, Brummett B, Williams R. Vulnerability genes or plasticity genes? Mol Psychiatry 2009; 14: 746-754.

37. Jedema HP, Gianaros PJ, Greer PJ, Kerr DD, Liu S, Higley JD et al. Cognitive impact of genetic variation of the serotonin transporter in primates is associated with differences in brain morphology rather than serotonin neurotransmission. Mol Psychiatry 2010; 15: 512$522,446$.

38. Homberg JR, Lesch KP. Looking on the bright side of serotonin transporter gene variation. Biol Psychiatry 2011; 69: 513-519.

39. O'Rourke H, Fudge JL. Distribution of serotonin transporter labeled fibers in amygdaloid subregions: implications for mood disorders. Biol Psychiatry 2006; 60: 479-490.

40. Emiliano AB, Cruz T, Pannoni V, Fudge JL. The interface of oxytocin-labeled cells and serotonin transporter-containing fibers in the primate hypothalamus: a substrate for SSRIs therapeutic effects? Neuropsychopharmacology 2007; 32: 977-988.

41. Yu K, Qiu CL, Yang GB, Zong CM, Xing H, Shao Y et al. Alteration of serotonin transporter messenger RNA level in the peripheral blood mononuclear cells from simian/human immunodeficiency virus infected Chinese rhesus macaques (Macaca mulatta). Brain Behav Immun 2010; 24: 298-305.

42. Heinz A, Higley JD, Gorey JG, Saunders RC, Jones DW, Hommer D et al. In vivo association between alcohol intoxication, aggression, and serotonin transporter availability in nonhuman primates. Am J Psychiatry 1998; 155: 1023-1028.

43. Singh YS, Sawarynski LE, Michael HM, Ferrell RE, Murphey-Corb MA, Swain GM et al. Boron-doped diamond microelectrodes reveal reduced serotonin uptake rates in lymphocytes from adult rhesus monkeys carrying the short allele of the 5-HTTLPR. ACS Chem Neurosci 2010; 1: 49-64.

44. Bradberry CW, Rubino SR. Phasic alterations in dopamine and serotonin release in striatum and prefrontal cortex in response to cocaine predictive cues in behaving rhesus macaques. Neuropsychopharmacology 2004; 29: 676-685.

45. Centeno ML, Reddy AP, Smith LJ, Sanchez RL, Henderson JA, Salli NC et al. Serotonin in microdialysate from the mediobasal hypothalamus increases after progesterone administration to estrogen primed macaques. Eur J Pharmacol 2007; 555: 67-75.

46. Mason JN, Farmer H, Tomlinson ID, Schwartz JW, Savchenko V, DeFelice LJ et al. Novel fluorescence-based approaches for the study of biogenic amine transporter localization, activity, and regulation. J Neurosci Methods 2005; 143: 3-25.

47. Tomlinson ID, Iwamoto H, Blakely RD, Rosenthal SJ. Biotin tethered homotryptamine derivatives: high affinity probes of the human serotonin transporter (hSERT). Bioorg Med Chem Lett 2011; 21: 1678-1682. 
48. Park J, Quaiserova-Mocko V, Patel BA, Novotny M, Liu A, Bian X et al. Diamond microelectrodes for in vitro electroanalytical measurements: current status and remaining challenges. Analyst 2008; 133: 17-24.

49. Perez XA, Bianco LE, Andrews AM. Filtration disrupts synaptosomes during radiochemical analysis of serotonin uptake: comparison with chronoamperometry in SERT knockout mice. J Neurosci Methods 2006; 154: 245-255.

50. Bengel D, Murphy DL, Andrews AM, Wichems $\mathrm{CH}$, Feltner D, Heils A et al. Altered brain serotonin homeostasis and locomotor insensitivity to 3, 4-methylenedioxymethamphetamine ("Ecstasy") in serotonin transporter-deficient mice. Mol Pharmacol 1998; 53: 649-655.

51. Andrews AM, Ladenheim B, Epstein CJ, Cadet JL, Murphy DL. Transgenic mice with high levels of superoxide dismutase activity are protected from the neurotoxic effects of 2'-NH2-MPTP on serotonergic and noradrenergic nerve terminals. Mol Pharmacol 1996; 50: 1511-1519.

52. Luellen BA, Miller DB, Chisnell AC, Murphy DL, O'Callaghan JP, Andrews AM. Neuronal and astroglial responses to the serotonin and norepinephrine neurotoxin: 1-methyl-4-(2' aminophenyl)-1,2,3,6-tetrahydropyridine. J Pharmacol Exp Ther 2003; 307: 923-931.

53. Perez XA, Andrews AM. Chronoamperometry to determine differential reductions in uptake in brain synaptosomes from serotonin transporter knockout mice. Anal Chem 2005; 77: 818-826.

54. Baganz NL, Horton RE, Calderon AS, Owens WA, Munn JL, Watts LT et al. Organic cation transporter 3: keeping the brake on extracellular serotonin in serotonin-transporterdeficient mice. Proc Natl Acad Sci USA 2008; 105: 18976-18981.

55. Kalin NH, Shelton SE, Fox AS, Rogers J, Oakes TR, Davidson RJ. The serotonin transporter genotype is associated with intermediate brain phenotypes that depend on the context of eliciting stressor. Mol Psychiatry 2008; 13: 1021-1027.

56. Heils A, Teufel A, Petri S, Stober G, Riederer P, Bengel D et al. Allelic variation of human serotonin transporter gene expression. J Neurochem 1996; 66: 2621-2624.

57. Nobile M, Begni B, Giorda R, Frigerio A, Marino C, Molteni M et al. Effects of serotonin transporter promoter genotype on platelet serotonin transporter functionality in depressed children and adolescents. J Am Acad Child Adolesc Psychiatry 1999; 38: 1396-1402.

58. Anderson GM, Gutknecht L, Cohen DJ, Brailly-Tabard S, Cohen JH, Ferrari $P$ et al. Serotonin transporter promoter variants in autism: functional effects and relationship to platelet hyperserotonemia. Mol Psychiatry 2002; 7: 831-836.

59. Kaiser R, Muller-Oerlinghausen B, Filler D, Tremblay PB, Berghofer A, Roots I et al. Correlation between serotonin uptake in human blood platelets with the 44-bp polymorphism and the 17-bp variable number of tandem repeat of the serotonin transporter. Am J Med Genet 2002; 114: 323-328.

60. Patkar AA, Berrettini WH, Mannelli P, Gopalakrishnan R, Hoehe MR, Bilal L et at Relationship between serotonin transporter gene polymorphisms and platelet serotonin transporter sites among African-American cocaine-dependent individuals and healthy volunteers. Psychiatr Genet 2004; 14: 25-32.

61. Willeit M, Stastny J, Pirker W, Praschak-Rieder N, Neumeister A, Asenbaum S et al. No evidence for in vivo regulation of midbrain serotonin transporter availability by serotonin transporter promoter gene polymorphism. Biol Psychiatry 2001; 50: 8-12.

62. Naylor L, Dean B, Pereira A, Mackinnon A, Kouzmenko A, Copolov D. No association between the serotonin transporter-linked promoter region polymorphism and eithe schizophrenia or density of the serotonin transporter in human hippocampus. Mol Med 1998; 4: 671-674

63. Heinz A, Jones DW, Mazzanti C, Goldman D, Ragan P, Hommer D et al. A relationship between serotonin transporter genotype and in vivo protein expression and alcohol neurotoxicity. Biol Psychiatry 2000; 47: 643-649.

64. van Dyck CH, Malison RT, Staley JK, Jacobsen LK, Seibyl JP, Laruelle M et al. Central serotonin transporter availability measured with [123l]beta-CIT SPECT in relation to serotonin transporter genotype. Am J Psychiatry 2004; 161: 525-531.

65. Murphy DL, Fox MA, Timpano KR, Moya PR, Ren-Patterson R, Andrews AM et al. How the serotonin story is being rewritten by new gene-based discoveries principally related to SLC6A4, the serotonin transporter gene, which functions to influence all cellular serotonin systems. Neuropharmacology 2008; 55: 932-960.

66. Munafo MR, Durrant C, Lewis G, Flint J. Gene X environment interactions at the serotonin transporter locus. Biol Psychiatry 2009; 65: 211-219.

67. Risch N, Herrell R, Lehner T, Liang KY, Eaves L, Hoh J et al. Interaction between the serotonin transporter gene (5-HTTLPR), stressful life events, and risk of depression: a meta-analysis. JAMA 2009; 301: 2462-2471.

68. Rutter M, Thapar A, Pickles A. Gene-environment interactions: biologically valid pathway or artifact? Arch Gen Psychiatry 2009; 66: 1287-1289.
69. Uher R, McGuffin P. The moderation by the serotonin transporter gene of environmental adversity in the etiology of depression: 2009 update. Mol Psychiatry 2009; 15: 18-22.

70. Barr CS, Newman TK, Shannon C, Parker C, Dvoskin RL, Becker ML et al. Rearing condition and rh5-HTTLPR interact to influence limbic-hypothalamic-pituitary-adrenal axis response to stress in infant macaques. Biol Psychiatry 2004; 55: 733-738.

71. Schwandt ML, Lindell SG, Sjoberg RL, Chisholm KL, Higley JD, Suomi SJ et al. Geneenvironment interactions and response to social intrusion in male and female rhesus macaques. Biol Psychiatry 2010; 67: 323-330.

72. Montanez S, Daws LC, Gould GG, Frazer A. Serotonin (5-HT) transporter (SERT) function after graded destruction of serotonergic neurons. J Neurochem 2003; 87: 861-867.

73. Mathews TA, Fedele DE, Coppelli FM, Avila AM, Murphy DL, Andrews AM. Gene dosedependent alterations in extraneuronal serotonin but not dopamine in mice with reduced serotonin transporter expression. J Neurosci Methods 2004; 140: 169-181.

74. Homberg JR, Olivier JD, Smits BM, Mul JD, Mudde J, Verheul M et al. Characterization of the serotonin transporter knockout rat: a selective change in the functioning of the serotonergic system. Neuroscience 2007; 146: 1662-1676.

75. Holmes A, Lit Q, Murphy DL, Gold E, Crawley JN. Abnormal anxiety-related behavior in serotonin transporter null mutant mice: the influence of genetic background. Genes Brain Behav 2003; 2: 365-380.

76. Li Q, Wichems C, Heils A, Van De Kar LD, Lesch KP, Murphy DL. Reduction of 5hydroxytryptamine $(5-\mathrm{HT})(1 \mathrm{~A})$-mediated temperature and neuroendocrine responses and 5-HT(1A) binding sites in 5-HT transporter knockout mice. J Pharmacol Exp Ther 1999; 291: 999-1007.

77. Tjurmina OA, Armando I, Saavedra JM, Goldstein DS, Murphy DL. Exaggerated adrenomedullary response to immobilization in mice with targeted disruption of the serotonin transporter gene. Endocrinology 2002; 143: 4520-4526.

78. Bartolomucci A, Carola V, Pascucci T, Puglisi-Allegra S, Cabib S, Lesch KP et al. Increased vulnerability to psychosocial stress in heterozygous serotonin transporter knockout mice. Dis Model Mech 2010; 3: 459-470.

79. Holmes A, Yang RJ, Murphy DL, Crawley JN. Evaluation of antidepressant-related behavioral responses in mice lacking the serotonin transporter. Neuropsychopharmacology 2002; 27: 914-923.

80. Olivier JD, Van Der Hart MG, Van Swelm RP, Dederen PJ, Homberg JR, Cremers T et al. A study in male and female 5-HT transporter knockout rats: an animal model for anxiety and depression disorders. Neuroscience 2008; 152: 573-584.

81. Nonkes LJ, Tomson K, Maertin A, Dederen J, Maes JH, Homberg J. Orbitofrontal cortex and amygdalar over-activity is associated with an inability to use the value of expected outcomes to guide behaviour in serotonin transporter knockout rats. Neurobiol Learn Mem 2010; 94: 65-72.

82. Numis AL, Unger EL, Sheridan DL, Chisnell AC, Andrews AM. The role of membrane and vesicular monoamine transporters in the neurotoxic and hypothermic effects of 1-methyl4-(2'-aminophenyl)-1,2,3,6-tetrahydropyridine (2'-NH(2)-MPTP). Mol Pharmacol 2004; 66: 718-727.

83. Kim DK, Tolliver TJ, Huang SJ, Martin BJ, Andrews AM, Wichems C et al. Altered serotonin synthesis, turnover and dynamic regulation in multiple brain regions of mice lacking the serotonin transporter. Neuropharmacology 2005; 49: 798-810

84. Anderson GM, Bennett AJ, Weld KP, Pushkas JG, Ocame DM, Higley JD. Serotonin in cisternal cerebrospinal fluid of rhesus monkeys: basal levels and effects of sertraline administration. Psychopharmacology (Berl) 2002; 161: 95-99.

85. Ansorge MS, Morelli E, Gingrich JA. Inhibition of serotonin but not norepinephrine transport during development produces delayed, persistent perturbations of emotional behaviors in mice. J Neurosci 2008; 28: 199-207.

86. Popa D, Lena C, Alexandre C, Adrien J. Lasting syndrome of depression produced by reduction in serotonin uptake during postnatal development: evidence from sleep, stress, and behavior. J Neurosci 2008; 28: 3546-3554.

87. Plagnol V, Uz E, Wallace C, Stevens H, Clayton D, Ozcelik T et al. Extreme clonality in lymphoblastoid cell lines with implications for allele specific expression analyses. PLoS One 2008; 3: e2966.

Translational Psychiatry is an open-access journal published by Nature Publishing Group. This work is licensed under the Creative Commons Attribution-Noncommercial-No Derivative Works 3.0 Unported License. To view a copy of this license, visit http://creativecommons.org/licenses/by-nc-nd/3.0/ 